\title{
Developing an evaluation tool to provide a 360-degree reflection on work-integrated learning in accounting education
}

\author{
Gemma K. Lewis ${ }^{\mathrm{a} *}$, Belinda Williams ${ }^{\mathrm{b}}$, Stephen Allen ${ }^{\mathrm{c}}$, Beverly Goldfarb ${ }^{\mathrm{d}}$, Kevin Lyall ${ }^{\mathrm{e}}$, Rose \\ Kling $^{\mathrm{f}}$, and Peta Statham ${ }^{\mathrm{g}}$ \\ *Corresponding Author \\ ${ }^{a}$ College of Business and Economics, University of Tasmania, Launceston, Australia \\ Gemma.Lewis@utas.edu.au; ORCiD:org/0000-0003-1195-024X \\ ${ }^{b}$ College of Business and Economics, University of Tasmania, Launceston, Australia ORCiD: \\ org/0000-0002-0688-1940 \\ ${ }^{c}$ College of Business and Economics, University of Tasmania, Burnie, Australia ORCiD:org/ \\ 0000-0001-7626-9004 \\ ${ }^{d}$ College of Business and Economics, University of Tasmania, Launceston, Australia \\ ${ }^{e}$ College of Business and Economics, University of Tasmania, Launceston, Australia \\ ${ }^{f}$ College of Business and Economics, University of Tasmania, Hobart, Australia ORCiD: \\ org/0000-0002-3057-6938 \\ ${ }^{g}$ College of Business and Economics, University of Tasmania, Hobart, Australia
}

In the higher education environment, work-integrated learning (WIL) is widely considered a key component of developing work-ready and professional graduates. Quality evaluation systems are needed to ensure continual improvement and development of WIL programs focusing on all stakeholder perspectives, not just the students or the sponsoring organisations. This paper describes the process a team of business academics and educational developers at an Australian university adopted to design a 360-degree approach to WIL evaluation, using action research methodology. The team developed an evaluation tool, comprising an online survey and associated web-enabled platform. The tool was trialled in a final year accounting unit, which had recently introduced a placement-based WIL project. Peer reflections from WIL educators across our institution in addition to internal testing, complemented our findings regarding what further changes were required to make this innovative tool applicable to different WIL contexts and disciplines.

Keywords: WIL, evaluation, accounting, online survey, feedback, Australia 


\section{Introduction}

In today's ever-changing environment, universities need to move beyond the traditional educational approach and provide authentic experiences that transition students from academic learner to industry professional. This requires graduates to possess both theoretical knowledge, and the capability to apply this in a workplace. The increased demand for work-ready employees (Kavanagh \& Drennan, 2008; Jackson, 2010; Natoli et al., 2013; Smith et al., 2014), has resulted in a rise in work-integrated learning (WIL) across the higher education sector (Jackson, 2015; Universities Australia, 2019).

The broad perspective generally views WIL as encompassing arrangements where students undertake learning in an external workplace as part of their higher education studies (TEQSA, 2017) and is considered a form of collaboration between external professional environments and tertiary institutions (Brimble et al., 2012). While becoming more commonplace in the higher education sector, WIL is yet to be a widespread component of professional accounting education or the wider business curriculum (Abeysekera, 2006; Chiang, 2008; Smith et al., 2014; Rook \& McManus, 2016). This is despite the changing nature of the accounting profession due to technological advancements (Still and Clayton, 2004), and evidence over time pointing to the need for employability skills in accounting graduates (Kavanagh \& Drennan, 2008; Jackling \& de Lange, 2009; Stanley, 2017; Stanley \& Xu, 2019). The environment is slowly changing due to an increased focus by the accounting professional bodies on both technical and professional competency areas in preparing work-ready graduates, with evidence pointing to the benefits of WIL in universities that have embedded it into their accounting programs (Paisey \& Paisey, 2010; Stanley, 2013; Stanley \& Xu, 2019), and pressure within the wider higher education sector to provide graduates who are both academically sound and work ready (Larkin \& Beatson, 
2014; Smith-Ruig, 2014). Indeed, a recent study that obtained the views of Heads of Accountancy Schools in Australian universities found strong support for the future of WIL in the accounting discipline (Stanley \& Xu, 2019). However, with no compulsory WIL mandated by professional bodies unlike other degree structures (e.g., nursing, medicine), this has led to a lack of focus on WIL in the accounting curriculum. As WIL becomes increasingly popular with governments, students and industry (Reeders, 2000; Abeysekera, 2006) and with studies examining its benefits (Fallon, 2012), the broader business discipline must seriously consider this form of learning to ensure their graduates' work-readiness.

Appropriately designed evaluation and improvement mechanisms need to be in place to ensure successful WIL experiences for the students and the other stakeholders who take part. Merely providing practice-based programs is insufficient if there is no opportunity for reflection and reconciliation of the contribution of those experiences (Billet, 2011). The literature primarily focuses on evaluation through a single lens (i.e., student perceptions) with limited studies examining other stakeholder viewpoints, either as singular or multiple viewpoint studies (Smith et al., 2006; Papakonstantinou et al., 2013; Jackson et al., 2017a \& b). Pilgrim (2012) argues for clearer motivations from all stakeholders involved in WIL, to ensure the future of this learning approach. Similarly, Stanley and Xu (2019) suggest there has been very limited research on accounting employer and accounting educator perspectives of WIL. To achieve improved outcomes for all stakeholders, their perceptions and understanding need to be understood (Patrick et al., 2009; Smith, 2012; Dukhi et al., 2014), using a carefully planned and executed process. Without this, only a limited understanding of WIL can be gained through the evaluation process. 
In this paper we seek to contribute to the literature and to educational practice by describing how WIL was incorporated into an undergraduate accounting program, while simultaneously reflecting on our experience of designing an innovative evaluation tool that could collect feedback from all stakeholders who were involved in the trial of this new initiative. Recognising that a lack of evaluative mechanisms specific to WIL currently restrict continuous improvement, the results of our action research indicate the tool could be used for continual improvement in developing work-ready professional students across disciplines, particularly when applied to work-placement initiatives.

The remainder of this paper is structured as follows. Firstly, an overview of WIL is provided, noting the growing interest in WIL from within the business and accounting disciplines. This is followed by a brief review of relevant literature on the evaluation of WIL, then a description of the WIL initiative and the subsequent evaluation tool that our team developed. Next, we explain how the team implemented and refined the tool, using an action research methodology. The conclusion section at the end of our paper presents the recommendations and main implications for future practice and research.

\section{WIL initiatives in the business discipline}

A growing body of literature points to the inadequacy of graduates' traditional reliance on strong disciplinary knowledge to secure employment post-University (e.g., Kavanagh \& Drennan, 2008; Jackson, 2013b \& 2013c; Jackson \& Wilton, 2017). Today, employers demand more of graduates in terms of their relevant experience, work-readiness and non-technical skills to operate effectively in the workplace (ACEN, 2015; Dolce et al., 2020; Edwards et al., 2015; McMurray et al., 2016; McManus \& Rook, 2019). WIL, a technique used to assist in improving the work-readiness of students (Freudenberg et al., 2010; Smith et al., 2014), is becoming a significant feature 
of both the Australian and international higher education landscape (Reddan \& Rauchle, 2012; Stanley \& Xu, 2019).

There is some debate within the literature as to what WIL encompasses (see for example, Katula \& Threnhauser, 1999; Reeders, 2000; Beard \& Wilson, 2002), though historically it has been held to include such diverse practices as work placements, internships, professional employment, industry-based learning and cooperative education, and more recently, experiential education or live case studies. These WIL formats and practices seek to achieve commonly expected outcomes of 'gaining new knowledge, understandings and capabilities, and mastering skills considered essential to particular workplace practices' (Orrell, 2011, p. 5).

It is important to note that the nature and scope of WIL varies (Trigwell \& Reid, 1998), which is arguably linked to discipline norms, the extent to which WIL has been embedded in the curriculum, and the availability of external partners. Nursing students, for example, often undertake semester-long placements, which require them to 'work' one or more days a week in a professional setting or workplace. This approach to WIL typically encompasses a long-term relationship between the external partner and the higher education provider, accepting multiple students year after year. In comparison, a WIL project for accounting students may involve them spending only one or two days in the external partner's workplace over the course of an entire semester, working a number of weeks with an employer organisation, or having the students simply presenting solutions to a workplace problem via a live case study method. Given that WIL and service learning has only recently been accepted as a 'serious contender' in the business academic realm (Smith-Ruig, 2014; Stanley, 2017), the 'employer' may likely be new to WIL, as may be their relationship with the higher education provider. 
The literature cites numerous benefits associated with WIL regardless of scope and nature. Patrick et al. (2009) considers the fundamental benefit is equipping students with the necessary skills employers are seeking; others see it as providing a link between academic theory and workplace practice (Smith et al., 2009; Reddan \& Rauchle, 2012; Smith, 2012; Jackson, 2013a). WIL has also been found to help students gain insight into the realities of their chosen career (Accenture, 2013) and improve their understanding of ethical behaviour (Woodley \& Beattie, 2011). Jackson (2013a), using a survey approach, found strong support for the role of WIL in developing graduate employability with the greatest skill perceived by students being 'professionalism'. As noted earlier, WIL has traditionally been somewhat lacking in business degree offerings (Smith et al., 2014). This is evidenced in studies such as Natoli et al. (2013), who found a gap between the assessment practices in accounting and the institutional WIL policy, with Abeysekera (2006) adding that WIL programs are not frequently practised in accounting programs in Australia.

Though some studies have noted the difficulties in implementing WIL in the business domain (e.g. Jackson, 2015; Stanley, 2017), others have highlighted the benefits that could be derived from this form of learning. This includes Beck and Halim (2008) who surveyed 250 students in Singapore following an 8-week internship and found social and interpersonal skills were significant outcomes of the experience. Stanley (2013) highlighted the value of accountancy placements from the student perspective through analysis of a Workplace Learning Experience Program at an Australian University. Specific benefits noted by the students included the importance of being engaged in an authentic learning experience, assistance with career decisions and in the transition from university to the workplace. Similarly, Paisey and Paisey (2010) found work placement within accounting degrees to be a useful complement to 
more traditionally structured degrees, noting the importance of skill development such as data analytical skills, IT upskilling, and time and stress management skill development. While Gracia (2010), in noting the importance of employability upskilling in the accounting curriculum, emphasised the importance of preparing students (and stakeholders) before the commencement of WIL programs to ensure expectations are clearly defined. With employers expressing increasing concerns over business graduates' demonstrated preparedness for employment (Jackling \& de Lange, 2009; Business Council of Australia, 2011; Lawson et al., 2011; Jackson \& Chapman, 2012; Jackson, 2013b; Smith et al., 2014; Abbasi et al., 2018; McManus \& Rook, 2019), it is clear there is growing interest in WIL programs in the business discipline domain.

\section{A stakeholder approach to an evaluation of WIL initiatives}

The literature argues that evaluation systems incorporating monitoring, analysis and improvement mechanisms are required for successful WIL models (Orrell, 2011; Edwards et al., 2015). However, Freestone et al. (2007) noted that this has been a longstanding educational concern with the major force towards improving WIL programs over time primarily originating from academic staff reflections (Reeders, 2000). The approach to WIL evaluation is slowly changing, with more recent research centring on the stakeholder's viewpoint, but these perceptions have largely been focused through a single lens, that being the student. For example, Reddan and Rauchle (2012) examined students' perceptions of WIL, noting not only the added value that 'career development learning' brings to WIL, but also the need to embed this form of learning within assessment. Other studies have focused solely on student perceptions (Freestone et al., 2007; Freudenberg et al., 2010; Spowart, 2011; Fallon, 2012; Jackson, 2013a; Smith \& Worsfold, 2014; Dukhi et al., 2014). 
Beyond this student perspective, very few studies have focused on other stakeholder viewpoints, except for Jackson et al. (2017a), who examined employer perspectives of WIL, including their understanding, reasons for participation and challenges/barriers posed during the WIL process. Stanley's (2017) research also offers useful insight regarding employer perceptions, specifically of work placement programs in accountancy. Using a qualitative approach, Stanley (2017) highlighted a number of costs and benefits, notably the substantial amount of time it takes for employers to look after students. When Smith et al. (2006) interviewed industry mentors for their views on what constitutes a successful placement, they found mixed views in understanding the role and motivations for industry involvement in the educational process. Some studies have focused on dual perspectives, including Jackson et al. (2017b), who evaluated via electronic survey both host employers and university students, focusing on the level of support through the WIL process and satisfaction with outcomes achieved respectively. Prior to this, Papakonstantinou et al. (2013) reported on the results of a study that evaluated the student and supervisor viewpoint of a research capstone scheme program that partnered with industry stakeholders. Others have observed that a wider, multilayered stakeholder approach is required to provide for a 'richer, more textured, and more complete picture of the focus of evaluation' (Dukhi et al., 2014, p. 4). Patrick et al. (2009) highlighted the need to recognise different stakeholder perspectives to create more meaningful linkages and 'help produce the adaptive, adaptable and transformative employees of the future' (p. 43). In calling for quality WIL outcomes for all stakeholders, Smith (2012) noted the need for a carefully planned and executed evaluation process.

Whilst the interest in WIL programs and initiatives is increasing, a review of current literature indicates a lack of evidence of evaluation systems in the WIL area 
developed from a multi-layered stakeholder approach. Our tool was designed to address this gap, whereby the expectations and perceptions of all parties involved in an accounting WIL project could be collected via a 360-degree approach to WIL evaluation. The following section sets out the initial context and environment for the development of the evaluation tool.

\section{Implementing a new WIL initiative in an undergraduate accounting program}

The WIL initiative was undertaken in an undergraduate Business degree course at our regional Australian University. The final year compulsory Auditing unit in the accounting major was chosen as the pilot unit to conduct the initiative. The unit was delivered to 112 undergraduate accounting students from both domestic and international backgrounds and taught using a face-to-face approach across three campuses as part of normal semester delivery.

\section{Characteristics of the WIL initiative}

The WIL initiative, designed as a multi-stakeholder approach, involved four parties: student teams, industry mentors, academic teaching staff and sponsoring organisations. Students were placed into teams of five. Students, teaching staff, industry mentors and the sponsoring organisations attended an initial orientation session about WIL. Three weeks of the auditing unit were fully dedicated to students undertaking a WIL project, during which they were required to conduct an auditing task and write a group report.

Each team was initially assigned a sponsoring organisation from the not-forprofit or social enterprise sector. The organisation's role was to assist the student team with the WIL project, provide the necessary information to help progress the team's project and assist teaching staff in assessing the outcomes of the team's project. The decision to embed the initiative in the not-for-profit sector was informed partly by prior 
research, which indicated this sector is more likely than private organisations to engage in WIL (Phillips KPA, 2014, p. 22).

Each student team was also assigned an industry mentor, who was an experienced practising auditor, not employed by the sponsoring organisation. The mentors were viewed as 'sounding boards' for the students if difficulty was encountered during their project. Mentors could also provide advice to the team about how to work professionally and how to source information needed to progress their assignment. In line with literature indicating the importance of supportive mentors for advice and feedback purposes (Martin et al., 2011; Smith et al., 2006), the inclusion of industry mentors provided an additional learning opportunity for the accounting students, but also created another layer for reflective practice for the teaching staff.

The teaching staff members were responsible for facilitating the WIL project within the curricula, including setting up the project (teams, mentors and organisations), conducting orientation sessions, overseeing the project, handling operational issues, and assessing the work produced by each student team with input from the sponsoring organisation and the industry mentor, in line with the developed assessment rubric. The project counted for 30 per cent of the student's final mark in the unit. In completing this task, students were assessed on their ability to gain an understanding of the sponsoring organisation's (i.e. the client) internal control system; document the internal control system using one of the accepted auditing methods; and provide a report to management on the strengths and weaknesses of the internal control system. The following section explains the action research approach we took in developing the WIL evaluation tool, which was subsequently pilot tested in the auditing unit.

\section{An Action Research Approach}


As previously indicated, currently there is a lack of evaluation systems using a multifocus, or 360-degree approach (Jackson et al., 2017a and b; Stanley 2017; Smith et al., 2006). In response, our evaluation tool was designed to capture data and reflections from all stakeholders involved in a WIL project. As such, it was determined an action research approach would be a suitable method to design and develop the evaluation tool, with five distinct stages.

Action research has been defined in many ways with Coghlan and BrydonMiller (2014, p. xxv) defining it as 'a global family of related approaches that integrate theory, and action with the goal of addressing important organizational, community and social issues together with those who experience them'. This form of research is focused on diagnosing practical problems through the lens of continual review, development and change (Paisey \& Paisey, 2003, 2005; Williams et al. 2019; Hazelton \& Haigh, 2010). It was noted by Kaplan (1998), action research also has a role in understanding 'conditions for successful implementation in organizations' (p. 90). In the higher education environment, action research has been utilised for the purposes of designing and implementing improvements to educational practice (for example, Patrick et al., 2009; Smith et al., 2009; Harris et al., 2010). Notwithstanding recognition that this approach is a suitable method for small-scale studies, (McGrath \& Murphy, 2016; Hazelton \& Haigh, 2010; Paisey, 2003, 2005) action research remains under-utilised in the accounting context (Curtis, 2017). Previous studies conducted in the accounting education field have included, for example, a focus on student participation and engagement (Malan, 2020; Williams et al, 2019; McGrath \& Murphy, 2016); transferrable skill development (Paisey \& Paisey, 2010) and incorporation of specified content into the curricula (Hazelton \& Haigh, 2010; Paisey \& Paisey, 2003). Given the aims of this project was to obtain multi-level feedback and generate self- 
reflective enquiry as the tool progressed, we deemed an action research approach to be the most suitable method, which is in line with similar studies by Schonell and Macklin (2018i) and Curtis (2017). As shown in Figure 1, the approach we adopted was informed by the cycle outlined by Curtis (2017) and involved: Stage 1: Recognising a need for change, Stage 2: Developing the evaluation tool, Stage 3: Pilot testing the evaluation tool, Stage 4: Seeking interdisciplinary reflections, Stage 5a: Making sense and developing Version 2.0 and Stage 5b: Sharing lessons learnt. These five stages that comprised our model are discussed in more detail below.

Figure 1. The action research cycle (Curtis, 2017)

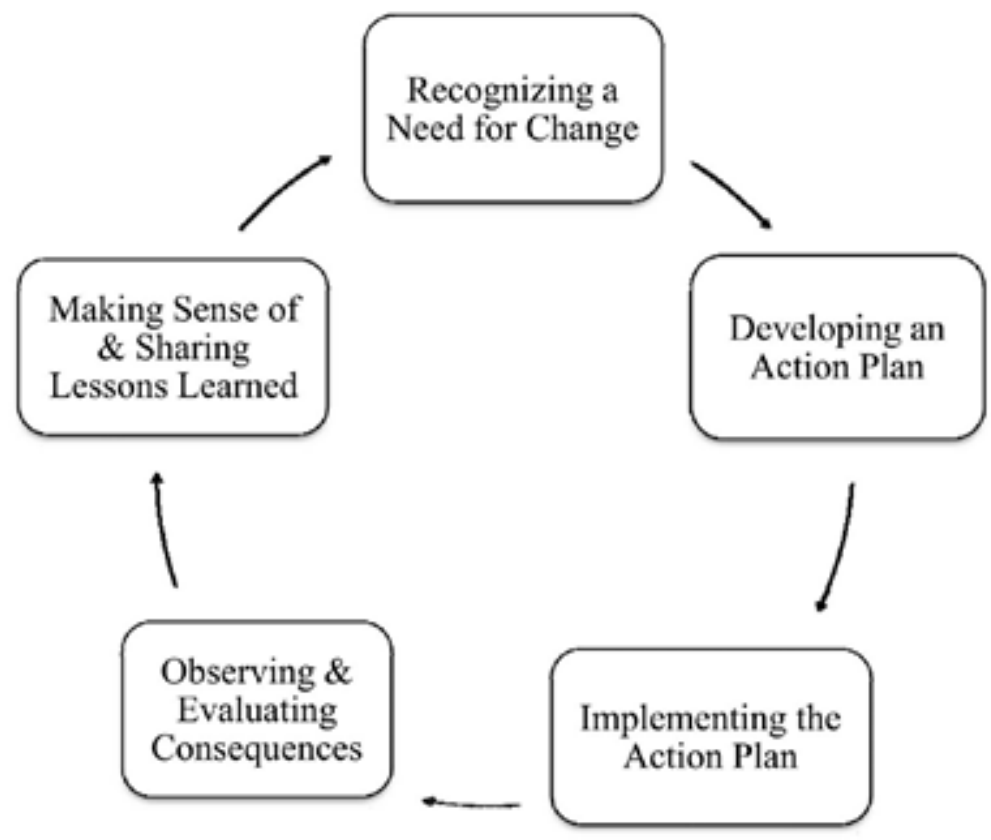

\section{Implementing the Five Stages of Action Research}

\section{Stage One: Recognising a need for change}

The first stage of our project commenced with our team recognising there was a need for change following feedback received in response to a local industry reference group. Specifically, the group noted that the accounting major offered within the undergraduate 
Business degree was not adequately preparing students with work-ready skills. It was determined a WIL approach would be utilised to provide an authentic experience, rather than adopt a traditional classroom approach to address this issue. A proposal (which was subsequently accepted) was provided to the industry reference group to ensure support at a professional level. Our research team then identified that in order to continually improve the WIL initiative, it would be important to have an evaluation mechanism which could accurately capture feedback from all the stakeholders involved. Following this, an internal teaching development grant application was submitted by the research team for the development of a WIL evaluation tool. The 'grant team' comprised accounting and management academics and professional staff experienced in working with technology-enhanced teaching tools and software. The make-up of the team provided for a diverse range of skills and knowledge, both scholarly and practical in nature.

Once grant funding was received, we invited a leading international expert on WIL to share the latest insights and advancements in WIL and discuss the team's vision for our evaluation tool. In preparation for this visit, the team held a series of meetings reflecting on our own experiences and understanding of WIL, and more broadly our knowledge of teaching-evaluation strategies. During the expert's visit, we hosted an internal seminar, bringing together 26 academics and professional staff from the wider University community, who were actively involved in, or simply interested in, WIL. This seminar initiated new dialogue regarding the evaluation of WIL and provided another set of experiences and insight for us to consider in the evaluation tool's design and development. In addition, we conducted a literature review to identify best practice in WIL evaluation and to identify any existing evaluation tools that had been empirically validated. The review also incorporated desktop research of WIL guides 
(for example, Ferns, 2014) and conference proceedings, recognising that innovation in WIL happens within both practitioner and academic circles.

\section{Stage Two: Developing the evaluation tool}

From Stage one, we determined that our evaluation tool would comprise an online selfadministered survey, with an associated platform where survey results could be illustrated in a 360-degree interactive format, providing a holistic representation of the WIL project's strengths and weaknesses and allowing for improvements to its design and delivery. This is in line with Smith (2012), who suggests feedback provided via evaluation tools should be used to enhance the outcomes and process of future WIL activity. Additionally, Jackson (2015) found that many problems experienced by students participating in WIL can be attributed to poor placement design, and ineffective avenues for information exchange and feedback mechanisms.

The survey approach was chosen due to its suitability as documented in prior studies that have evaluated WIL (see, for example, Venville, Lynch \& Santhanam, 2018; Jackson, 2015; Smith, 2012; Walker et al. 2013). Additionally, a self-reporting survey was considered the most suitable tool for capturing structured data from a range of stakeholders (i.e. students, staff, sponsoring organisations and mentors) in a convenient manner (De Vaus, 2014; Neuman, 2012). The online survey platform we used also allowed us to administer different questions to different audiences depending on which stakeholder group they belonged to.

The team then developed the survey in accordance with the literature and sought ethics approval to pilot test our online survey within the auditing unit's new WIL initiative. The first version of our survey comprised 29 questions, grouped into six sections outlined as per below (see Appendix A). We also included an open-text box 
after each question, enabling the collection of qualitative data regarding the respondent's answers and overall perception of the project.

The introductory section of the survey contained one compulsory question that identified which 'WIL participant category' the respondent represented (i.e. student, host organisation, industry mentor or academic coordinator/teaching staff). The respondent's answer to this question determined which group of survey questions they were asked. Section two of the survey comprised six 'industry mentor' questions that were measured using a 4-point Likert scale ranging from strongly agree to strongly disagree. These questions were designed to measure the mentor's overall impression of the WIL project, and their perceptions of the students who participated. We adopted a 4point Likert scale to avoid a mid- or neutral point. According to Chyung et al. (2017), including a mid-point is suitable when the researchers intend to calculate average scores and perform certain statistical analysis. In our study, we were focused on refining the questions and structure of our tool, rather than analysing the pilot survey data using statistical techniques. Hence, we considered it appropriate to require respondents to make a choice between agree and disagree. A similar approach was used by Walker et al. (2013), when they surveyed students regarding perceptions of support they received during their WIL experience.

Section three comprised six 'teaching staff' questions, designed to gather feedback from the academic unit coordinators and other educators involved in the WIL project. These questions covered topics such as support for the project, resources, and the extent to which the 'teacher' had the necessary skills and knowledge to be involved in the WIL project. Again, a 4-point Likert scale ranging from strongly agree to strongly disagree was used. 
Section four comprised six questions targeted to students. The literature places significant importance on evaluating the student's WIL experience (Smith \& Worsford, 2014; Jackson, 2015) but appears to focus primarily on student learning outcomes (Reddan, 2013). In contrast, we were interested in evaluating the student's perspective of the design and operational delivery of the WIL project. As such, our questions measured the extent to which students felt the experience enhanced their academic degree and employability prospects, the extent to which they applied subject theory, their ability to meet the time commitment required, and their rating of both the host organisation and industry mentor. Most questions in this section were measured using a 4-point Likert scale; however, one question used a simple yes/no response, relating to whether the student was able to meet the time commitment required for the WIL project.

Section five comprised six 'host organisation' questions, which allowed us to gain insights into the operational parameters of WIL projects (Smith, 2012) and the perceived return of investment. In 2015, Atkinson et al. found that employers in STEM disciplines were reluctant to participate in WIL initiatives due to lack of time and resources to invest in the students and lack of staff suitable for supervision. This, along with the learning we obtained from our expert visit, informed the type of questions included in this section. In addition, sponsoring (host) organisations were asked about whether students engaged with them in a professional and appropriate manner, in line with recent studies that highlight the importance of soft skills for accounting graduates (Dolce et al., 2020).

The final section of the survey contained four general questions for all participants. The first two related to the extent to which the respondent felt they received adequate information about the WIL project, and were measured using a 4- 
point Likert scale ranging from strongly agree to strongly disagree. The third question related to whether the respondent would be interested in participating in this type of WIL project again, and the final, open-ended question allowed for any final comments or suggestions that might improve future WIL projects conducted by the business school and/or university.

\section{Stage Three: Pilot testing the evaluation tool}

Following ethics approval, the research team conducted trials of the evaluation tool (i.e. the online survey and associated results platform) within the auditing unit WIL initiative, described earlier in this paper. All students enrolled in the auditing unit ( $n$ $=112$ ), as well as a sample of sponsoring organisations, industry mentors and teaching staff, were invited (via email) to complete the evaluation survey. The survey's landing page summarised the aims of our grant and a statement informing respondents that by completing the voluntary and confidential survey, they consented to taking part in the research. The survey was launched in the final week of the semester in 2016 and closed after four weeks. This timing allowed participants time to reflect on their experience of the WIL initiative.

In total, 49 participants completed the survey, yielding a response rate of 39 percent. Of this, 31 were students, 11 sponsoring organisations, 5 industry mentors, and 2 teaching staff. The first version of our associated results platform was developed in Microsoft Excel using a VBA macro. This allowed the raw survey data to be inputted generating a visual representation of the 360-degree feedback received (see Figure 2, known as Version 1.0).

Figure 2. Version 1.0 visual representation using Microsoft Excel. 


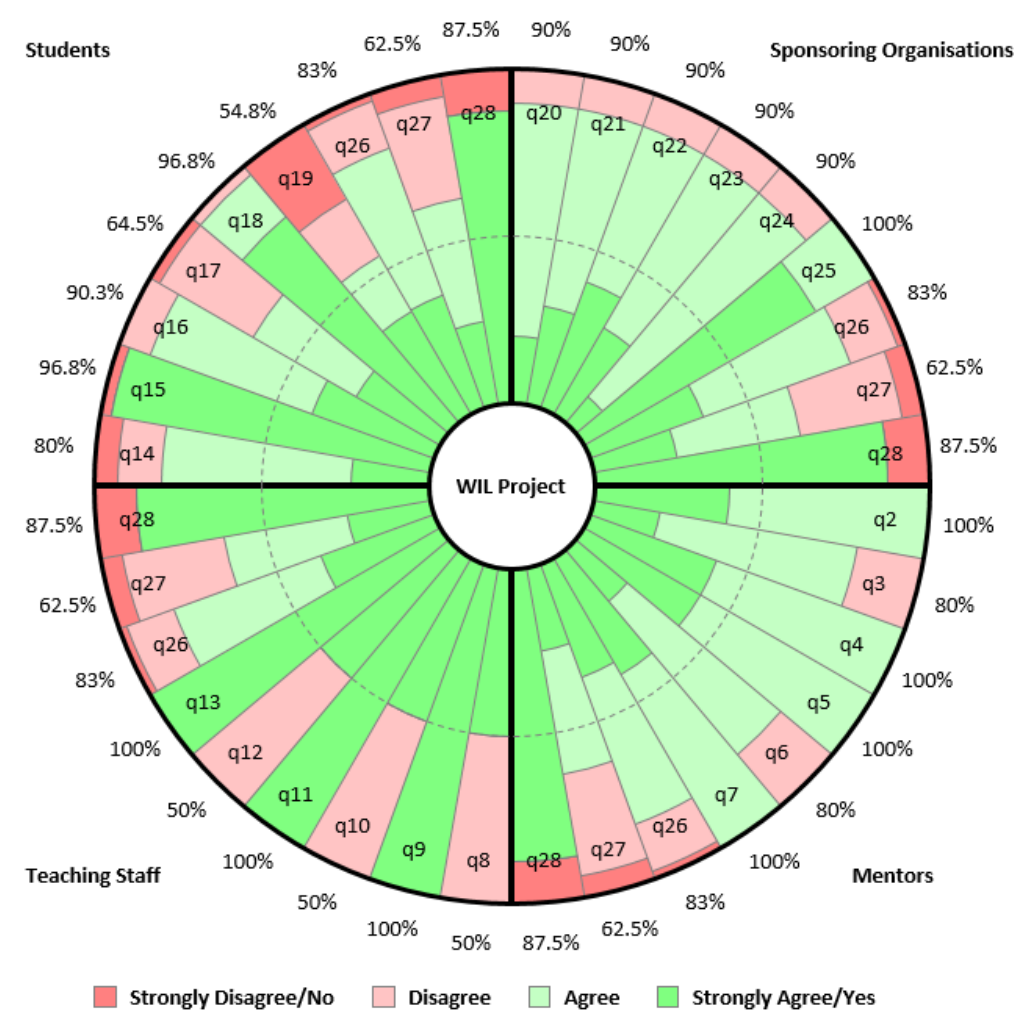

Notes: For a list of the corresponding questions please see Appendix A. The outside percentages represent the total agreement, i.e., the sum of both the Strongly Agree and Agree survey responses.

\section{Stage Four: Seeking interdisciplinary reflections}

After developing Version 1.0 of our results platform, reflections were sought via informal interviews with teaching staff from other disciplines (e.g., health, information systems and engineering) on both the design of our initial evaluation survey, and the format of the Excel Figure 2. These conversations identified several refinements that would make our tool more user-friendly, meaningful, and applicable to other WIL contexts (i.e., not just work placements or industry projects). Two members of our research team also presented at a WIL Community of Practice forum, during which additional reflections were obtained.

Based on these peer reviews, we changed the design of our evaluation survey so users could create their own questions, as well as selecting from the bank of questions provided in Appendix A, to suit the type of WIL activity being implemented and the 
different disciplinary contexts. During this stage we also modified how the results of the survey were presented, so that users could interact better with the results platform. As highlighted above, in our initial version, results were presented in an 'interactive' manner using an illustration created via a Microsoft Excel spreadsheet. However, peer reflections suggested that this platform (i.e., MS Excel) and the Figure 2 itself was confusing and difficult to interpret. We also wanted a way to list the questions alongside any results illustration, without making it overly complex and thus, explored alternative software platforms to increase the tool's sophistication and visual representation. Stage Five below discusses the results of these explorations splitting the stage into two components; a) Making sense of and b) Sharing lessons learnt.

\section{Stage Five(a): Making sense of and developing Version 2.0}

From Stage Four of our action research cycle, it became clear that an alternative platform was required. The team investigated a range of options and observed that Google Forms and Google Sheets offered a suitable alternative for developing a more interactive results platform. This stage involved the engagement of external consultants who assisted us in developing a more sophisticated results platform, but simple enough to navigate and use by independent course coordinators or WIL educators. In addition, we recognised the need to have an associated website or 'landing page' (see Figure 3 below) where users could find out more about our project and request and customise their own 360-degree WIL evaluation survey.

Figure 3. Landing page where users can create their own survey. 


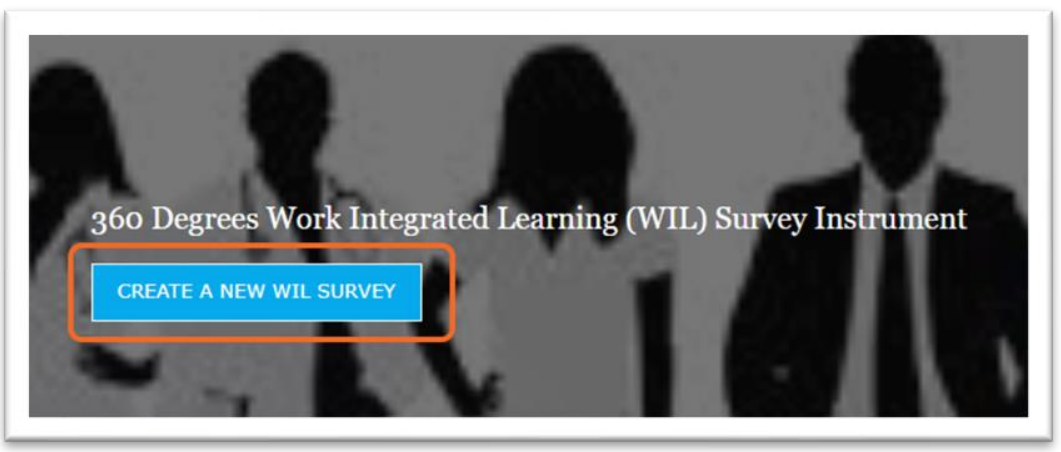

As shown in Figure 4, the second version of our results platform was significantly different from Version 1.0, both in functionality and visual appearance. The level of interactivity was also much greater, allowing users to display results in a dashboard style according to a specific survey question or respondent category (i.e. stakeholder group). Displaying results in a dashboard style (and in real-time) is commonplace in industry because it allows users to visualise their progress, and/or assess an outcome easily. Essentially dashboards aggregate large amounts of data into a simple and meaningful visual display.

Figure 4. Version 2.0 visual representation using a dashboard style.

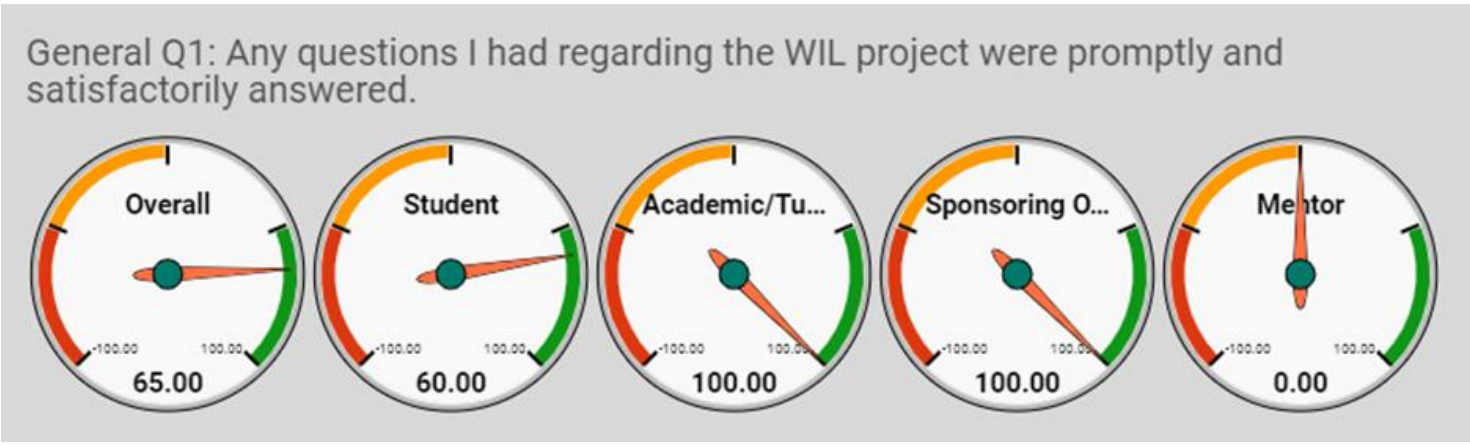

Another advantage of Version 2.0 was that it was fully contained within a webbased environment, obviating the need to download or install specific software to request a survey, or importantly view, or share results with others. The open-ended question results and qualitative data were displayed under the dashboard, making it accessible and easy to read. Importantly, when requesting a survey (administered via the 
Google Forms platform), users also had the option to modify our recommended survey questions (see Appendix A) or write their own. As shown in Figure 5 below, this was simply done by clicking the question text to edit the wording, and/or the answer options.

Figure 5. Sample question that users could edit or customise in one click.

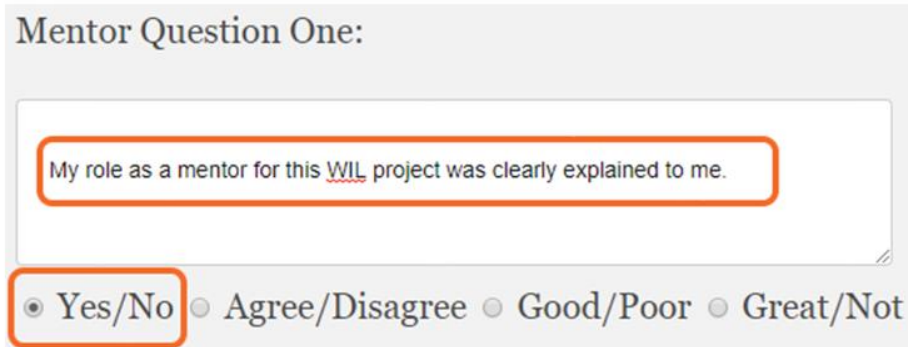

When a user created their own survey, an email was received comprising a link that could be sent to the relevant stakeholders involved in their own WIL initiative. At the same time, a unique website was generated for their WIL initiative, where the results of their evaluation survey would be displayed and updated in real time, via Google Sheets. Only the user requesting the survey and the administration member of our project team (who was the owner of the Google account) were able to access this website, thus providing for a level of data security not previously afforded by Version 1 of our tool.

Thorough testing was conducted on Version 2.0 utilising the survey data gathered previously to test the accuracy of the tool but also, to ensure that the process for implementing a web-based WIL evaluation survey was user-friendly and appealing to people who had no prior experience with WIL evaluation. Email exchanges and virtual meetings with the external consultants enabled further refinement, particularly in terms of the survey layout and visual appearance. The consultants also undertook their own testing to check the survey creation process was robust. When the research team 
were satisfied Version 2.0 was working as efficiently as it could within the time and financial resource constraints of our grant, the external consultants formally handed over the final product $\mathrm{i}^{\mathrm{i}}$

\section{Stage Five(b): Sharing lessons learnt}

To seek peer feedback on the refined instrument, we first presented Version 2.0 of our tool at our university's annual 'Teaching Matters' conference. This presentation also enabled us to discuss our learnings and to further refine the tool based on the feedback received. Following the feedback, we wrote an accompanying user guide to provide instructions to other teaching teams (e.g., at our higher education institution) should they wish to use our tool to evaluate their own WIL initiatives.

At this point, our team reflected on how our individual understandings of WIL had evolved since we first met as a research team to discuss the problems we sought to address. Through the process of obtaining peer reflections and presenting our tool to diverse audiences, we increased our awareness of and appreciation for the range of WIL initiatives; how the understanding of what WIL is (and is not) varied according to who we spoke to and their discipline; and how educators, students and external stakeholders experienced WIL. Similarly, we observed how the understanding of (and focus on) WIL at an institutional level was evolving. Our university's teaching and learning division was preparing materials (such as a website and unit coordinator survey) concurrently about WIL. Within our business school, developments were also occurring in terms of the appointment of WIL teaching fellows and 'career and WIL officers'. The WIL initiative developed for the auditing unit has since being used by our School as an exemplar of innovative teaching practices to inform others both internal and external to the university 1. 


\section{Conclusions, Implications and Future Research}

Across all disciplines, the demand for work-ready employees is on the increase with a greater emphasis being placed on WIL programs in the higher education sector (Jackson, 2010, 2015). The need for WIL in accounting education curriculum has been highlighted by the accounting professional bodies through stronger focus on both technical and professional competency areas. Further, with increased interest in wordready programs from government, students, and industry (Abeysekera, 2006; Stanley \& $\mathrm{Xu}, 2019)$, the implementation of WIL will continue to evolve in the broader business curriculum area.

From a practical perspective, our action research suggests change is required at an institutional level if a 360-degree approach to WIL evaluation is to be successfully implemented and maintained. This incorporates the need to work beyond specific disciplines, and with stakeholders external to the education provider to deliver mutual benefit for all involved. Establishment of policies that clearly articulate and encompass the wider community is critical to this process, noted also by Reddan and Rauchle (2012) who found that universities need to integrate their services with industry partners 'to produce graduates who can not only find satisfying employment but also successfully manage their lifelong careers' (p. 46).

Another implication of this study is the need for professional development for both academics and those external to the university who are involved in WIL to equip them with the skills and knowledge in working with the students. Given the evolving nature of WIL in the higher education sector and the focus on innovative WIL initiatives such as virtual WIL and combining WIL with mobile technology, it is likely that our tool will need to evolve and adapt, just as other forms of teaching and learning evaluations have done in the past. 
This study identified a research gap in appropriately designed WIL evaluation mechanisms, given the current literature has a focus on evaluating WIL through a single lens. By describing the action research process our team followed in designing and developing a 360-degree reflective tool, we contributed to the literature using a multi stakeholder approach, thus providing a 'richer, more textured and more completed picture of the focus of evaluation' (Dukhi et al., 2014, p. 4). In contributing to practice, this tool could be effectively utilised to improve outcomes for students and all stakeholders, through a shared understanding of the WIL experience (Patrick et al, 2009). Moreover, our paper contributes to the literature through offering a detailed guide of how educators and institutions can improve the evaluation of WIL initiatives.

Future research could focus on how Version 2.0 of our evaluation tool could be utilised to better inform development of WIL practices across different contexts, such as in a discipline other than accounting and in WIL projects that go beyond the traditional work placement format or across institutions. Further work is also recommended due to the small sample size utilised in the pilot testing stage of this study, and, as Malan (2020) identified, application across different contexts would allow learnings through the action learning approach. With limited application of action research methodology to the accounting education literature, further research would also encourage pockets of innovation, in an effort towards broader acceptance of WIL within the accounting education curriculum (Curtis, 2017).

\section{Note}

1 For a copy of the evaluation tool, please contact the corresponding author.

Acknowledgements: This research was supported by an internal teaching development grant funded by the University of Tasmania. Our thanks go to those who shared their expertise and feedback and assisted in developing (and revising) our evaluation tool. 


\section{References}

Abbasi, F., Ali, A., \& N. Bibi. (2018). Analysis of Skill Gap for Business Graduates: Managerial Perspective from Banking Industry. Education+ Training, 60(4), 354-367.

Abeysekera, I. (2006). Issues relating to designing a work-integrated learning program in an undergraduate accounting degree program and its implications for the curriculum. Asia-Pacific Journal of Cooperative Education, 7, 7-15.

Accenture. (2013). College Graduate Employment Survey. Accenture.

Atkinson, G., Misko, J., \& Stanwick, J. (2015). Work integrated learning in STEM disciplines: the employer perspective. Australia: National Centre for Vocational Education Research.

Australian Collaborative Education Network Limited (ACEN). (2015). National Strategy on Work Integrated Learning in University Education. Australia: ACEN.

Barnett, R. (2004). Learning for an unknown future. Higher Education Research and Development, 23(3), 247-260.

Beard, C., \& Wilson, J. P. (2002). The power of experimental learning: A handbook for trainers and educators. London: Kogan Page.

Beck, J. E., \& Halim, H. (2008). Undergraduate internships in accounting: What and how do Singapore interns learn from experience. Accounting Education, 17(2), $151-172$.

Billet, S. (2011). Curriculum and pedagogic bases for effectively integrating practicebased experiences. Strawberry Hills, NSW: Australian Learning and Teaching Council (ALTC).

Brimble, M., Cameron, C., Freudenberg, B., Fraser, C., \& MacDonald, K. (2012). Collaborating with industry to enhance financial planning and accounting education. Australasian Accounting, Business and Finance Journal, 6(4), 79-93.

Business Council of Australia. (2011). Skills for prosperity: A roadmap for vocational education and training. Melbourne: Business Council for Australia.

Chiang, B. (2008). Integrating a service-learning project into management accounting coursework: A sharing of implementation experience and lessons learned. Accounting Education: An International Journal, 17(4), 431-445. 
Chyung, S.Y., Roberts, K., Swanson, I. \& Hankinson, A. (2017). Evidence-based survey design: The use of a midpoint on the Likert scale. Performance Improvement, 56(10), 15-23.

Coghlan, D., \& Brydon-Miller, M. (2014). Introduction. In D. Coghlan \& M. BrydonMiller (Eds.), The SAGE encyclopaedia of action research (pp. xxv-xxvi). Retrieved from https://books.google.com.au/books?hl=en\&lr=\&id=hNfSAwAAQBAJ\&oi=fnd $\& p g=P P 1 \& d q=$ Coghlan+and+BrydonMiller\&ots=LnLMYcNVes\&sig=yfsYD3 1j8S6W3u_UmOVhrduXdb0\#v=onepage \&q=Coghlan\%20and\%20BrydonMiller\&f=false

Curtis, S. M. (2011). Formative assessment in accounting education and some initial evidence on its use for instructional sequencing. Journal of Accounting Education 29: 191-211.

Curtis, S.M. (2017). Pathway to reform: Developing action research capacity in accounting education. Issues in Accounting Education, 32(3), 51-79.

Dacre Pool, L., \& Sewell, P. (2007). The key to employability: developing a practical model of graduate employability. Education and Training, 49(4), 277-289.

de Vaus, D. A. (2014). Surveys in Social Research. 6th Edition. Sydney: Allen and Unwin.

Dolce, V., Emanuel, F., Cisi, M., \& Ghislieri, C. (2020). The soft skills of accounting graduates: Perceptions versus expectations. Accounting Education, 29(1), 57-76.

Dukhi, N., Southwood, S., \& Srinivas, S. C. (2014). Evaluating students' experience of an integrated assessment: A case study in health promotion. Indian Journal of Pharmaceutical Education and Research, 48(3), 1-5.

Edwards, D., Perkins, K., Pearce, J., \& Hong, J. (2015). Work Integrated Learning in STEM in Australian Universities: Final Report. Camberwell, Australia: Australian Council for Educational Research.

Fallon, W. (2012). Flashpoints in students' work-integrated learning in business: Implications for curriculum design. Employment Relations Record, 12(1), 6680.

Ferns, S. (2014). Work integrated learning in the curriculum. Australia: Higher Education Research and Development Society of Australasia. 
Freestone, R., Williams, P., Thompson, S., \& Trembath, K. (2007). A quantitative approach to assessment of work-based learning outcomes: an urban planning application. Higher Education Research and Development, 26(4), 347-361.

Freudenberg, B., Brimble, M., \& Vyvyan, V. (2010). The penny drops: Can work integrated learning improve students' learning? e-journal of Business Education and Scholarship of Teaching, 4(1), 42-61.

Gracia, L. (2010). Accounting students' expectations and transition experiences of supervised work experience. Accounting Education, 19(1-2), 51-64.

Harris, L., Jones, M., \& Coutts, S. (2010). Partnerships and learning communities in work-integrated learning: designing a community services student placement program, Higher Education Research \& Development, 29(5), 547-559.

Hazelton, J. \& Haigh, M. (2010). Incorporating sustainability into accounting curricula: Lessons learnt from an action research study, Accounting Education: An International Journal, 19(1-2), 159-178.

Ingersoll Abbott, J. \& Palatnik, B.R, (2018). Students' perceptions of their first accounting class: implications for instructors, Accounting Education, 27(1), 7293

Jackling, B., \& de Lange, P. (2009). Do Accounting Graduates' Skills Meet the Expectations of Employers? A Matter of Convergence or Divergence. Accounting Education: An International Journal, 18(4-5), 369-385.

Jackson, D. (2009). Undergraduate management education: Its place, purpose and efforts to bridge the skills gap. Journal of Management and Organization, 15,(2), 206-223.

Jackson, D. (2010). An international profile of industry-relevant competencies and skill gaps in modern graduates. International Journal of Management Education, $8(3), 29-58$.

Jackson, D. (2013a). The contribution of work-integrated learning to undergraduate employability skill outcomes. Asia-Pacific Journal of Cooperative Education 14(2), 99-115.

Jackson, D. (2013b). Business graduate employability: Where are we going wrong? Higher Education Research and Development, 32(5), 776-90. 
Jackson, D. (2013c). Student perceptions of the importance of employability skills provision in business undergraduate programs. Journal of Education for Business, 88(5), 271-9.

Jackson, D. (2015). Employability skill development in work-integrated learning: Barriers and best practice. Studies in Higher Education, 40(2), 350-367.

Jackson, D., \& Chapman, E. (2012). Non-technical skills gaps in Australian business graduates. Education + Training, 54(2), 95-113.

Jackson, D., \& Wilton, N. (2017). Perceived employability among undergraduates and the importance of career self-management, work experience and individual characteristics. Higher Education Research and Development, 36(4), 747-762.

Jackson, D., Rowbottom, D., Ferns, S., \& McLaren, D. (2017a). Employer understanding of work-integrated learning and the challenges of engaging in work placement opportunities. Studies in Continuing Education, 39(1), 35-51.

Jackson, D., Ferns, S., Rowbottom, D., \& Mclaren, D. (2017b). Improving the workintegrated learning experience through a third-party advisory service. International Journal of Training Research, 15(2), 160-178.

Kaplan, R. S. (1998). Innovation action research: creating new management theory and practice. Journal of Management Accounting Research, 10, 89-118.

Katula, R. A., \& Threnhauser, E. (1999). Experiential education in the undergraduate curriculum. Communication Education, 48(3), 238-255.

Kavanagh, M., \& Drennan, L. (2008). What skills and attributes does an accounting graduate need? Evidence from student perceptions and employer expectations. Accounting \& Finance, 48(2), 279-300.

Larkin, I., \& Beatson, A. (2014). Blended delivery and online assessment: Scaffolding student reflections in work-integrated learning. Marketing Education Review, 24(1), 9-14.

Lawson, R., Fallshaw, E., Papadopoulos, T., Taylor, T., \& Zanko, M. (2011). Professional learning in the business curriculum: Engaging industry, academics and students. Asian Social Science, 7(4), 61-68.

Malan, M. (2020). Engaging students in a fully online accounting degree: an action research study, Accounting Education, 29(4), 321-339.

Martin, A., Rees, M., \& Edwards, M. (2011). Work-integrated learning. A template for good practice: Supervisors' reflections. Wellington, NZ: Ako Aotearea. 
McGrath, D. \& Murphy, D. (2016). Understanding accounting as a career: An immersion work experience for students making career decisions, Accounting Education, 25(1), 57-87.

McManus, L., \& Rook, R. (2019). Mixed views in the academy: academic and student perspectives about the utility of developing work-ready skills through WIL. Studies in Higher Education. Advance online publication. doi: 10.1080/03075079.2019.1630809

McMurray, S., Dutton, M., McQuaid, R., \& Richard, A. (2016). Employer demands from business graduates, Education + Training, 58(1), 112-32.

Natoli, R., Jackling, B., Kaider, F., \& Clark, C. (2013). Mapping WIL activities in the curriculum to develop graduate capabilities: A case study of accounting. AsiaPacific Journal of Cooperative Education, 14(2), 75-88.

Neuman, W. (2012). Basics of social research: qualitative and quantitative approaches, $3^{\text {rd }}$ edition. Pearson, Boston.

Orrell, J. (2011). Good Practice Report: Work-integrated learning. Australian and Learning Teaching Council Ltd.

Paisey, C., \& Paisey, N. J. (2003). Developing research awareness in students: An action research project explored. Accounting Education: An International Journal, 12(3), 283-302.

Paisey, C., \& Paisey, N. J. (2005). Improving accounting education through the use of action research. Journal of Accounting Education, 23(1), 1-19.

Paisey, C., \& Paisey, N.J. (2010). Developing skills via work placements in accounting: Student and employer views. Accounting Forum, 34(2), 89-108.

Papakonstantinou, T., Charlton-Robb, K., Reina, R. D., \& Rayner, G. (2013). Providing research-focused work-integrated learning for high achieving science undergraduates. Asia-Pacific Journal of Cooperative Education, 14(2), 59-73.

Patrick, C., Peach, D., \& Packnee, C. (2009). The WIL (Work Integrated Learning) Report: A national scoping study [Australian Learning and Teaching Council (ALTC) Final report]. Brisbane: Queensland University of Technology.

Phillips KPA. (2014). Engaging employers in work integrated learning: current state and future priorities. Canberra: Commonwealth of Australia.

Pilgrim, C. (2012). Industry and university perspectives of work integrated learning Programs in ICT Degrees, in ACIS 2012: Location, location, location: 
Proceedings of the 23rd Australasian Conference on Information Systems 2012, ACIS, Geelong, Victoria.

Reddan, G. (2013). To grade or not to grade: Student perceptions of the effects of grading a course in work-integrated learning. Asia Pacific Journal of Cooperative Education, 14(4), 223-232.

Reddan, G., \& Rauchle, M. (2012). Student perceptions of the value of career development learning to a work-integrated learning course in exercise science. Australian Journal of Career Development, 21(1), 38-48.

Reeders, E. (2000). Scholarly practice in work-based learning: Fitting the glass slipper. Higher Education Research and Development, 19(2), 205-220.

Rook, L., \& McManus, L. (2016). Viewing WIL in business schools through a new lens. Emergence: Complexity and Organization, 18(2), 1-14.

Schonell, S., \& Macklin, R. (2018). Work integrated learning initiatives: live case studies as a mainstream WIL assessment. Studies in Higher Education, 44(7), $1197-1208$.

Smith, C. (2012). Evaluating the quality of work-integrated learning curricula: a comprehensive framework. Higher Education Research and Development, 31(2), 247-262.

Smith, C., \& Worsfold, K. (2014). WIL curriculum design and student learning: a structural model of their effects on student satisfaction. Studies in Higher Education, 39(6), 1070-1084.

Smith, C., Ferns, S., \& Russell, L. (2014). The impact of work integrated learning on student work-readiness (Final Report). Sydney: Office for Learning and Teaching.

Smith, M., Brooks, S., Lichtenberg, A., McIlveen, P., Torjul, T., \& Tyler, J. (2009). Career development learning: Maximising the contribution of work-integrated learning to the student experience (Final Project report). Sydney, Australia: University of Wollongong, Careers Central, Academic Services Division.

Smith, R. D., Mackay, D, Challis, D., \& Holt, D. (2006). Seeking industry perspectives to enhance experimental education in University-industry partnerships: Going beyond mere assumptions. Asia-Pacific Journal of Cooperative Education, 7(2), $1-9$. 
Smith-Ruig, T. (2014). Exploring the links between mentoring and work-integrated learning. Higher Education Research and Development 33(4), 769-782.

Spowart, J. (2011). Hospitality students competencies: Are they work ready? Journal of Human Resources in Hospitality and Tourism, 10(2), 169-181.

Stanley, T. (2013). Bridging the gap between tertiary education and work: Situated learning in accountancy. Issues in Accounting Education, 28(4), 779-799.

Stanley, T. (2017). Situated learning in accountancy: An employer perspective. Accounting Research Journal, 30(3), 265-282.

Stanley, T., \& Xu, J. (2019). Work-integrated learning in accountancy at Australian universities: Forms, future role and challenges. Accounting Education, 28(1), $1-$ 24.

Still, K., \& Clayton, P. (2004). Utilizing service-learning in accounting programs. Issues in Accounting Education, 19(4), 469-486.

Tertiary Education Quality and Standards Agency (TEQSA). (2017). Guidance Note: Work Integrated Learning Version 1.2. Australia: Tertiary Education Quality and Standards Agency.

Trigwell, K., \& Reid, A. (1998). Introduction: Work-based Learning and the students' perspective. Higher Education Research \& Development, 17(2), 141-154. Universities Australia. (2019). Career Ready Graduates. Deakin, Australia.

Venville, A., Lynch, B. \& Santhanam, E. (2018). A systematic approach to the evaluation of the student experience in Work-Integrated Learning. International Journal of Work-Integrated Learning, 19(1), 13-21.

Walker, S., Dwyer, T., Moxham, L., Broadbent, M. \& Sander, T. (2013). Facilitator versus preceptor: which offers the best support to undergraduate nursing students? Nurse Education Today, 33(5), 530-535.

Williams, B.R., Horner, C., \& Allen, S. (2019). Flipped v's traditional teaching perspectives in a first year accounting unit: an action research study, Accounting Education, 28(4), 333-352.

Wilton, N. (2012). The impact of work placements on skills development and career outcomes for business and management graduates. Studies in Higher Education, $37(5), 603-620$. 
Woodley, C., \& Beattie, S. (2011). Communal reflections on the workplace: Locating learning for the legal professional. Asia-Pacific Journal of Cooperative Education, 12, 19-30. 


\section{Appendix A. Survey questions created for Version 1 of our tool}

\section{OPENING QUESTION TO ALL SURVEY RESPONDENTS}

Q1. In relation to your involvement in the [insert project name here] WIL initiative, what was your role? (Student, Sponsoring Organisation, Mentor, Academic/tutor)

\section{INDUSTRY MENTOR QUESTIONS}

Q2. My role as a mentor for this project was clearly explained to me.

(Strongly Agree, Agree, Disagree, Strong Disagree, Additional Comments)

Q3. I was able to meet the time commitment required to be a WIL mentor.

(SA, A, D, SD, Additional Comments)

Q4. The student(s) engaged with me in a professional and appropriate manner.

(SA, A, D, SD, Additional Comments)

Q5. I had the necessary technical skills to mentor students in the completion of their assigned tasks.

(SA, A, D, SD, Additional Comments)

Q6. I felt that I was able to effectively mentor the student(s) in the completion of their assigned tasks.

(SA, A, D, SD, Additional Comments)

Q7. My involvement in this WIL project was a positive professional experience for me.

(SA, A, D, SD, Additional Comments)

\section{TEACHING STAFF QUESTIONS}

Q8. I had the support I needed from my manager (including discipline leadership) for this WIL project.

$$
\text { (SA, A, D, SD, Additional Comments) }
$$

Q9. I had the support I needed from professional and learning support staff for this WIL project.

(SA, A, D, SD, Additional Comments)

Q10. I had the resources I needed (both people and financial) for this WIL project.

(SA, A, D, SD, Additional Comments)

Q11. I had the necessary skills and knowledge to be involved as a teacher and/or assessor in this WIL project. 
(SA, A, D, SD, Additional Comments)

Q12. I felt that my involvement in this WIL project was highly regarded by my colleagues.

(SA, A, D, SD, Additional Comments)

Q13. Student engagement in the unit was enhanced as a result of this WIL project.

(SA, A, D, SD, Additional Comments)

\section{STUDENT QUESTIONS}

Q14. As an educational experience, this WIL project has enhanced my academic degree.

(SA, A, D, SD, Additional Comments)

Q15. I was able to meet the time commitment required for the WIL project.

(Yes, No, Additional Comments)

Q16. Did you apply (put into practice) any knowledge, skills or theory from [insert unit code] to this WIL project?

(Yes, a great deal; Yes, to some extent; No, not really; No, not at all, Additional Comments)

Q17. My participation in this WIL project enhanced my employability prospects.

(Yes, a great deal; Yes, to some extent; No, not really; No, not at all, Additional

Comments)

Q18. How would you rate your team's sponsoring organisation (e.g. in terms of their resources, environment and communication)?

(Very good, Good, Fair, Poor, Additional Comments)

Q19. How would you rate your team's mentor (e.g. in terms of their technical knowledge, support, advice)?

(Very good, Good, Fair, Poor, Additional Comments)

\section{SPONSORING ORGANISATION QUESTIONS}

Q20. My role as a sponsoring organisation for this WIL project was clearly explained to me.

(SA, A, D, SD, Additional Comments)

Q21. I was able to meet the time commitment required to be a WIL sponsor.

(SA, A, D, SD, Additional Comments) 
Q22. I was able to devote the resources needed to be a WIL sponsor within our organisational context.

(SA, A, D, SD, Additional Comments)

Q23. I was able to provide guidance and/or feedback to the student team.

(SA, A, D, SD, Additional Comments)

Q24. Given the benefits, it was worthwhile for our organisation to invest the time and effort in WIL.

(SA, A, D, SD, Additional Comments)

Q25. The students engaged with our organisation in a professional and appropriate manner.

(SA, A, D, SD, Additional Comments)

\section{GENERAL QUESTIONS FOR ALL RESPONDENTS AT END OF SURVEY}

Q26. Any questions I had regarding the WIL project were promptly and satisfactorily addressed.

(SA, A, D, SD, Additional Comments)

Q27. The WIL project orientation workshop provided the necessary information for my participation in the project.

(SA, A, D, SD, Additional Comments)

Q28. Would you be interested in participating in this type of WIL project again?

(Yes, No, Additional Comments)

Q29. Are there any additional comments or suggestions you would like to make to improve future WIL projects like this? 